\title{
The Impact of Common Chronic Conditions on Health-Related Quality of Life: A General Population Survey in Iran Using EQ-5D-5L
}

\section{Ali Akbari Sari}

Tehran University of Medical Sciences

\section{Fereshte Karimi}

Tehran University of Medical Sciences

\section{Zahra Emrani}

Tehran University of Medical Sciences

\section{Hojjat Zeraati}

Tehran University of Medical Sciences

Alireza Olyaeemanesh

Tehran University of Medical Sciences

Rajabali Daroudi ( $\nabla$ rdaroudi@sina.tums.ac.ir)

Tehran University of Medical Sciences

\section{Research}

Keywords: Health-Related Quality of Life, Chronic Disease, Economic Evaluation, EQ-5D, Iran

Posted Date: September 18th, 2020

DOl: https://doi.org/10.21203/rs.3.rs-78043/v1

License: (9) (i) This work is licensed under a Creative Commons Attribution 4.0 International License. Read Full License 


\section{Abstract}

\section{Background:}

Diseases have undeniable effects on Health-Related Quality of Life (HRQoL). Chronic diseases, in particular, limit the productive potentials and HRQoL of individuals. EQ-5D is a very popular generic instrument, which can be used to estimate HRQoL scores in any diseases. The current study investigates mean HRQoL scores in certain chronic diseases and examines the relationship between utility scores and chronic diseases in Iran.

\section{Method:}

This cross-sectional study was carried out among the general adult population of Tehran. 3060 individuals were chosen by a stratified probability sampling method. The EQ-5D-5L questionnaire was applied. The utility scores were estimated using the Iranian crosswalk-based value set. The effect of chronic diseases on the HRQoL scores was derived by the Ordinary Least Squares (OLS) method. Data was analyzed using Stata version 13 software.

\section{Results:}

The mean \pm standard deviation utility and EQ-VAS scores were $0.86 \pm 0.14$ and $77.50 \pm 16.14$ in the participants without any chronic conditions. The scores were $0.69 \pm 0.17$ and $61.61 \pm 20.39$ in the participants with chronic conditions. The highest and lowest mean utility scores were related to thyroid disease (0.70) and Stroke (0.54), respectively. Common chronic conditions had significant negative effects on the HRQoL scores. Stroke (0.204) and cancer (0.177) caused the most reduction in the EQ-5D$5 \mathrm{~L}$ utility scores. Lumbar disc hernia, digestive diseases, osteoarthritis, breathing problems, and anxiety/nerves cause $0.133,0.109,0.108,0.087$, and 0.078 reductions, respectively, in the EQ-5D-5L utility scores.

\section{Conclusion:}

This study provides insight into some common chronic conditions and their effects on the HRQoL. Policymakers and planners should pay attention to the effects of chronic conditions especially high prevalence one. They should adopt effective interventions to control this issue and increase health. The results of this study can also be beneficial in economic evaluation studies.

\section{Introduction:}

Chronic disease is one of the most common groups of diseases in the world, whose prevalence is estimated at about $15-40 \%$ in the developed countries [1-3]. Some examples of chronic diseases include cardiovascular disease, muscular dysfunction, osteoporosis, depression, frustration, social interactions and memory problems, and decreasing sexual activity $[4,5]$. These diseases have significant negative effects on the Health-Related Quality of Life (HRQoL), as they would impose direct and indirect costs to 
the community [6-9]. In recent years, the therapeutic, economic, and social effects of chronic diseases have been highly considered by researchers and policymakers [10].

The main objective of health care is to improve the individual's quality and quantity of life. The quality of life is a multidimensional structure that includes social factors and the physical, mental, and functional dimensions [11]. It can be measured and developed in different ways, [12]. Health-related quality of life, briefly known as HRQoL, is an individual's subjective view to the impact of the health condition on various aspects of his/her well-being and captures information on the impact of health status on quality of life[13]. In recent years, HRQoL has become an important health outcome indicator. There are several instruments for measuring HRQoL. Some are disease-specific (e.g., St George's asthma quality of life scale, NEWQOL-6D, EORTC QOL-30), while some are generic (e.g., EQ-5D, SF-6D, WHOQOL)[14].

EQ-5D is the most widely used generic preference-based instrument developed by EuroQol in 1990 [1518]. It is a multi-attribute instrument that considers five dimensions, including mobility, self-care, usual activities, pain/discomfort, and anxiety/depression. There are two versions of the EQ-5D instrument, which are EQ-5D-3L and EQ-5D-5L. The EQ-5D-5L questionnaire has five-level classifications of severity, including no problems, slight problems, moderate problems, severe problems, and extreme problems [19]. This questionnaire described $3125\left(5^{5}\right)$ health states. For simplicity, health states are indicated by numerical symptoms. For example, 11111 and 55555 show the best and the worst health states, respectively. The former score represents a health state that the person has no problems, while the latter indicates a health state that the person has extreme problems in all dimensions. Other health states are between these two scores [20]. The social value sets for EQ-5D have been produced in many countries, including Iran [21, 22]. The instrument also includes a visual analogue scale (EQ-VAS), which provides a single global rating of self-perceived health. It is scored on a 0 to $100 \mathrm{~mm}$ scale representing "the worst ..." and "the best health you can imagine", respectively.

Health policymakers need to know which chronic conditions have the greatest impact on HRQoL, and identify where additional intervention may be required. Therefore, the aim of this study was to investigate the impact of a wide range of chronic conditions on HRQoL in the general Iranian population.

\section{Method:}

\section{Survey:}

This cross-sectional observational study was carried out from October 2015 to March 2016 in Tehran, the capital of Iran, among the general adult population aged at least 18 years old. A sample of 3060 individuals was selected via a stratified probability sampling method. The target population was stratified by municipality, and from each stratum, a random sample with a size proportionate to the population was drawn. To select the respondents, each stratum (municipality region) was divided into several blocks.

Then, based on the sample size from each stratum, the required number of blocks for data collection was randomly selected. In each block, 10 households were randomly invited for the interview. The households 
with non-responses were replaced with households in the replacement list. The interviews were conducted face-to-face by some trained interviewers.

\section{Questionnaire:}

The questionnaire consisted of three main parts. First, it collected information on demographic characteristics, such as gender, age, education, marital status, and employment status. The second part was regarding the general health status questions about the respondent's viewpoints of his/her health and the presence of any illness or health problem in respondents or their family members. The presence of any illness or health problem was assessed with the question: "Do you have any illness, health problem, condition, or disability?". The participants who had a disease or health problem were asked to choose the name of the disease from a list or simply mention the name of the disease. It was possible to choose or mention more than one option. The third part was the EQ-5D-5L questionnaire to determine the participants' HRQoL scores.

\section{Statistical methods:}

To calculate the respondents' HRQoL scores according to the EQ-5D-5L questionnaire, we used the fivelevel crosswalk-based value set derived from the EQ-5D-3L value set in Iran [22]. we applied the crosswalk methodology developed by van Hout et al[23] to the Iranian EQ-5D-3L value set developed via a face-toface TTO method to obtain the Iranian crosswalk-based EQ-5D-5L value set[22].

The mean and standard deviation of the participants' HRQoL scores was calculated by common chronic diseases. Furthermore, the following regression model was estimated to determine the impact of common chronic diseases on participants' HRQoL.

$Q=a_{0}+a_{i} Z_{i}+\beta_{i} X_{i}$

$Q=H R Q o L$ score

$\mathrm{Zi}=$ Common chronic diseases

$\mathrm{Xi}=$ Demographic characteristics

In this model, the common chronic diseases were included as independent variables. They were defined in forms of dummy variables. For example, a dummy variable was defined for diabetes, which took two values: "1" for patients with diabetes and "0" for patients without diabetes. The Iranian crosswalk-based value set scores were considered as dependent variables in the 1st model and the EQ-VAS scores in the 2nd model. These models were estimated using the OLS method. The Breusch-Pagan test was used to verify the Heteroscedasticity in the regression model. The data were analyzed using Stata 13 software. 


\section{Results:}

Table 1 shows the demographic characteristics and the mean HRQoL scores of the participants. About $51 \%$ of the participants were female; the mean \pm standard deviation (SD) of the participants' age was 44 \pm 15.6 years; the average education years was $10.8 \pm 4$. 8 . About $77 \%$ of the subjects were married, $18 \%$ were single (never married), and $4.7 \%$ were divorced or widowed. The mean \pm SD utility and EQ-VAS scores of the participants were $0.80 \pm 0.17$ and $71.73 \pm 19.37$. 
Table 1

Demographic characteristics and mean HRQoL scores of participants $(n=3060)$

\begin{tabular}{|lll|}
\hline Variable & N & $\%$ \\
\hline Gender & & \\
\hline Male & 1,505 & 49.20 \\
\hline Female & 1,555 & 50.80 \\
\hline Employment status & & \\
\hline Employed & 1,079 & 35.30 \\
\hline Homemaker & 1,239 & 40.53 \\
\hline Retired & 396 & 12.95 \\
\hline Unemployed & 100 & 3.27 \\
\hline Student & 221 & 7.23 \\
\hline other & 22 & 0.07 \\
\hline Marital status & & \\
\hline Never married & 549 & 17.99 \\
\hline Married & 2,359 & 77.29 \\
\hline Widowed or Divorced & 144 & 4.72 \\
\hline Presence of any illness or health problem & & \\
\hline Yes & 1,115 & 36.46 \\
\hline No & 1,945 & 63.54 \\
\hline mean & SD \\
\hline Age (year) & 43.9 & 15.6 \\
\hline EQ-5D-5L utility scores & 10.85 & 4.79 \\
\hline EQ-VAS scores & 0.80 & 0.17 \\
\hline
\end{tabular}

Table 2 shows the prevalence of chronic conditions among participants as well as the mean EQ-5D-5L utility and EQ-VAS scores by common chronic conditions. Approximately $36 \%$ of the participants had at least one chronic condition. The mean \pm SD utility and EQ-VAS scores were $0.86 \pm 0.14$ and $77.50 \pm 16.14$ in the participants without any chronic conditions. The scores were $0.69 \pm 0.17$ and $61.61 \pm 20.39$ in the 
participants with chronic conditions. The most common conditions were psychological problems, including anxiety/nerves and depression (11.89\%), osteoarthritis (7.22\%), heart disease $(6.40 \%)$, hypertension $(6.8 \%)$, and diabetes $(5.62 \%)$. The utility scores were the lowest in stroke $(0.54)$ and cancer (0.58), while they were the highest in thyroid disease (0.70).

Table 2

Mean EQ-5D-5L utility and EQ-VAS scores by common chronic conditions

\begin{tabular}{|lllllll|}
\hline Chronic condition & $\mathbf{N}$ & $\begin{array}{l}\text { \% of total } \\
\text { participants }\end{array}$ & \multicolumn{2}{l}{$\begin{array}{l}\text { EQ-5D-5L utility } \\
\text { scores }\end{array}$} & \multicolumn{2}{l|}{ EQ-VAS scores } \\
\cline { 5 - 7 } & & & mean & SD & mean & SD \\
\hline $\begin{array}{l}\text { Without any chronic } \\
\text { condition }\end{array}$ & 1,945 & 63.54 & 0.86 & 0.14 & 77.50 & 16.14 \\
\hline With chronic condition & 1,115 & 36.46 & 0.69 & 0.17 & 61.61 & 20.39 \\
\hline Anxiety/nerves & 231 & 7.55 & 0.66 & 0.17 & 59.57 & 22.34 \\
\hline Osteoarthritis & 221 & 7.22 & 0.62 & 0.15 & 59.44 & 20.35 \\
\hline Heart disease & 196 & 6.40 & 0.67 & 0.17 & 58.49 & 19.97 \\
\hline Hypertension & 186 & 6.08 & 0.65 & 0.17 & 58.04 & 21.91 \\
\hline Diabetes & 172 & 5.62 & 0.67 & 0.18 & 57.64 & 21.67 \\
\hline Insomnia & 145 & 4.74 & 0.68 & 0.19 & 60.61 & 22.58 \\
\hline Depression & 133 & 4.34 & 0.66 & 0.16 & 58.82 & 22.76 \\
\hline Breathing problems & 60 & 1.96 & 0.67 & 0.19 & 60.03 & 19.81 \\
\hline Lumbar disc hernia & 44 & 1.44 & 0.65 & 0.16 & 61.67 & 19.71 \\
\hline Digestive diseases & 22 & 0.72 & 0.68 & 0.12 & 58.41 & 16.06 \\
\hline Cancer & 19 & 0.62 & 0.58 & 0.25 & 50.32 & 30.07 \\
\hline Stroke & 15 & 0.49 & 0.54 & 0.12 & 47.86 & 12.97 \\
\hline Thyroid disease & 15 & 0.49 & 0.70 & 0.12 & 70.13 & 19.46 \\
\hline Other & 117 & 3.82 & 0.67 & 0.18 & 58.69 & 21.73 \\
\hline
\end{tabular}

Table 3 shows the impact of chronic conditions on the HRQoL. The estimated coefficients were negative and statistically significant for all conditions except for insomnia and Thyroid disease. Stroke and cancer cause the most reduction in the HRQoL scores, which shows 0.204 and 0.177 reductions in the EQ-5D-5L utility scores and 18.11 and 17.31 reductions in EQ-VAS scores, respectively. According to model 1 , lumbar disc hernia, digestive diseases, osteoarthritis, breathing problems, and anxiety/nerves cause $0.133,0.109,0.108,0.087$, and 0.078 reductions, respectively, in the EQ-5D-5L utility scores. According to 
model 2, digestive diseases, other diseases, lumbar disc hernia, breathing problems, and diabetes cause $12.42,10.01,8.45,7.80$, and 7.55 reductions in the EQ-VAS scores. 
Table 3

The results of linear regression estimation to determine the impact of chronic diseases on HRQoL

\begin{tabular}{|c|c|c|c|c|}
\hline \multirow[t]{3}{*}{ Independent variable } & \multicolumn{4}{|c|}{ Dependent variable: quality of life score } \\
\hline & \multicolumn{2}{|c|}{ Model 1: EQ-5D-5 L utility scores } & \multicolumn{2}{|c|}{ Model 2: EQ_VAS scores } \\
\hline & Coefficient & Robust SE & Coefficient & Robust SE \\
\hline Gender(female) & $-0.024^{\star}$ & 0.009 & -0.40 & 1.01 \\
\hline Age (year) & $-0.002^{\star}$ & 0.000 & $-0.16^{\star}$ & 0.03 \\
\hline Years of schooling & $0.003^{*}$ & 0.001 & $0.33^{*}$ & 0.08 \\
\hline \multicolumn{5}{|l|}{ Employment status } \\
\hline Employed & Ref & & Ref & \\
\hline Student & -0.007 & 0.010 & 1.25 & 1.30 \\
\hline Home maker & $-0.028^{*}$ & 0.010 & -1.92 & 1.17 \\
\hline Retired & 0.015 & 0.010 & $3.04^{*}$ & 1.25 \\
\hline Unemployed & -0.018 & 0.015 & 1.36 & 1.92 \\
\hline Others & $-0.091^{\star}$ & 0.042 & -10.56 & 6.01 \\
\hline \multicolumn{5}{|l|}{ Marital status } \\
\hline Never married & Ref & & Ref & \\
\hline Married & -0.010 & 0.008 & -0.47 & 1.07 \\
\hline Divorce or widowed & $-0.046^{*}$ & 0.016 & $-5.79 *$ & 2.11 \\
\hline Anxiety/nerves & $-0.078^{*}$ & 0.011 & $-7.09 *$ & 1.53 \\
\hline Osteoarthritis & $-0.108^{*}$ & 0.010 & $-5.68^{\star}$ & 1.41 \\
\hline Heart disease & $-0.067^{\star}$ & 0.012 & $-7.20 *$ & 1.50 \\
\hline Hypertension & $-0.054^{\star}$ & 0.012 & $-4.79 *$ & 1.65 \\
\hline Diabetes & $-0.052^{*}$ & 0.014 & $-7.55^{\star}$ & 1.78 \\
\hline Insomnia & -0.022 & 0.014 & -2.43 & 1.88 \\
\hline Depression & $-0.074^{\star}$ & 0.013 & $-6.78^{\star}$ & 2.10 \\
\hline Breathing problems & $-0.087^{\star}$ & 0.022 & $-7.80 *$ & 2.49 \\
\hline Lumbar disc hernia & $-0.133^{*}$ & 0.025 & $-8.45^{\star}$ & 3.03 \\
\hline Digestive diseases & $-0.109 *$ & 0.029 & $-12.42^{*}$ & 3.46 \\
\hline
\end{tabular}




\begin{tabular}{|c|c|c|c|c|}
\hline \multirow[t]{3}{*}{ Independent variable } & \multicolumn{4}{|c|}{ Dependent variable: quality of life score } \\
\hline & \multicolumn{2}{|c|}{ Model 1: EQ-5D-5 L utility scores } & \multicolumn{2}{|c|}{ Model 2: EQ_VAS scores } \\
\hline & Coefficient & Robust SE & Coefficient & Robust SE \\
\hline Cancer & $-0.177^{\star}$ & 0.058 & $-17.31^{\star}$ & 7.17 \\
\hline Stroke & $-0.204^{\star}$ & 0.036 & $-18.11^{\star}$ & 3.44 \\
\hline Thyroid disease & -0.045 & 0.034 & 1.09 & 5.27 \\
\hline Other & $-0.097 *$ & 0.016 & $-10.01 *$ & 1.97 \\
\hline Intercept & $0.938^{*}$ & 0.018 & $80.29 *$ & 2.20 \\
\hline Number of observations & 3,041 & & 3024 & \\
\hline Adjusted R2 & 0.307 & & 0.199 & \\
\hline F statistic & $57.35^{\star}$ & & $25.22^{\star}$ & \\
\hline
\end{tabular}

\section{Discussion:}

In this study, we investigated the effect of chronic conditions on the HRQoL scores. The mean \pm SD utility and EQ-VAS scores were $0.86 \pm 0.14$ and $77.50 \pm 16.14$ in the participants without any chronic condition while the scores were $0.69 \pm 0.17$ and $61.61 \pm 20.39$ in the participants with chronic condition. The results showed that common chronic conditions had significant negative effects on the HRQoL scores. Stroke $(0.204 \pm 0.036)$, cancer $(0.177 \pm 0.58)$, lumbar disc hernia $(0.133 \pm 0.025)$, digestive diseases $(0.109 \pm$ $0.029)$, osteoarthritis $(0.108 \pm 0.010)$ caused the most reductions in the HRQoL scores. The mean HRQoL scores were the lowest among individuals with stroke $(0.54 \pm 0.12)$, cancer $(0.58 \pm 0.25)$, and osteoarthritis $(0.62 \pm 0.15)$ diseases.

Previous studies showed that common chronic diseases had a major effect on the HRQoL, which were similar to ours [24-27]. However, due to the differences in individuals' preferences in different societies, the effect of chronic diseases on the HRQoL may vary. A study in an elderly community-dwelling population in England showed the effects of common chronic diseases on the HRQoL using the EQ-5D questionnaire. The results suggested that most of these diseases reduce the HRQoL scores. Depression $(-0.269, P<0.001)$, neurological disease $(-0.172, P<0.0001)$, and osteoarthritis $(-0.081, P=0.0006)$ caused the greatest effects on the utility scores [25]. The results of a study on Sweden general population demonstrated that the HRQoL weighs were the lowest among individuals with depression, stroke, and low back pain. The scores were $(0.38 \pm 0.026),(0.44 \pm 0.035)$, and $(0.55 \pm 0.011)$ in people with these diseases. Regression analysis showed that depression, low back pain, and stroke caused $(0.4305 \pm$ $0.0270),(0.2810 \pm 0.0105)$, and $(0.2743 \pm 0.0366)$ reductions in the HRQoL $(P<0.0001)$ [24]. Another study on the general population in Finland showed that Parkinson's disease, anxiety disorders, arthrosis 
of the hip and knee, and depressive disorders were the most disabling chronic conditions based on EQ-5D, causing (0.201 \pm 0.063$),(0.169 \pm 0.019),(0.155 \pm 0.010)$, and $(0.139 \pm 0.016)$ reductions in mean utility scores, respectively. The mean utility scores were the lowest among individuals with Parkinson's disease $(0.440 \pm 0.068)$, heart failure $(0.585 \pm 0.017)$, and stroke $(0.587 \pm 0.023)[28]$.

A study in Hong Kong using the EQ-5D-5L questionnaire included four chronic diseases as an independent variable, whose effects were statistically significant on the HRQoL. The mean utility score for heart disease, hypertension, diabetes, and cancer was $0.882,0.881,0.874$, and 0.873 , respectively. In our study, these scores were $0.67,0.65,0.67$, and 0.58 , according to the Iranian crosswalk-based value set. The figures indicated that these diseases induced greater loss in Iranian HRQoL scores than the Chinese scores. [29].

The present study, for the first time, measured the association between chronic conditions and HRQoL via the EQ-5D-5L questionnaire in Iran. The EQ-5D-5L questionnaire is a general, reliable, and convenient measurement tool applied in the surveys of different diseases [29].

The main limitation of this study was the fact that we measured the prevalence of chronic diseases based on self-reporting. Although studies have shown the high degree of agreement between the actual prevalence of chronic diseases and people's self-declaration [30], this method is not completely accurate because some people might not be aware of their illness or its name.

\section{Conclusion:}

This study examined the effect of chronic conditions on the HRQoL scores using the EQ-5D-5L questionnaire in Iran. Almost all chronic conditions included in this study had a negative effect on HRQoL. Policymakers need to consider the increasing prevalence of chronic diseases in Iran due to the aging population and lifestyle changes. Additionally, they should pay attention to the elderly people who suffer from several chronic diseases at the same time. Hence, it is worthy of identifying the diseases with the greatest effect on the HRQoL. The effective interventions can be adopted and better prioritized. The results of this study can also be beneficial for researchers because the estimated utility weighs can be used in economic evaluation studies.

\section{List Of Abbreviations:}

Health-Related Quality of Life (HRQoL)

Ordinary Least Squares (OLS)

\section{Declarations:}

Ethics approval and consent to participate: 
This study was approved by the ethics committee of the Deputy of Research and Technology of the Tehran University of Medical Sciences (IR.TUMS.REC.1394.743). The participants were assured that their information would remain confidential. Informed consent was obtained from all individual participants included in the study.

\section{Consent for publication:}

Not applicable.

\section{Availability of data and materials:}

The datasets used and/or analyzed during the current study are available from the corresponding author on reasonable request.

\section{Competing Interests:}

The authors declare they have no conflict of interests.

\section{Funding:}

This study was funded by Tehran University of Medical Sciences (grant number 94-01-159-28771).

\section{Authors' contributions:}

All authors contributed to the study conception and design. Material preparation, data collection and analysis were performed by Ali Akbari Sari, Zahra Emrani, Hojjat Zeraati, Alireza Oliyaeemanesh, Fereshte Karimi and Rajabali Daroudi. The first draft of the manuscript was written by Rajabali Daroudi, Fereshte Karimi and Zahra Emrani and all authors commented on previous versions of the manuscript. All authors read and approved the final manuscript.

\section{Acknowledgements:}

not applicable.

\section{References:}

1. Gutteling J, De Man R, Busschbach J, Darlington A: Overview of research on health-related quality of life in patients with chronic liver disease. Neth J Med 2007, 65:227-234.

2. Vartiainen P, Mäntyselkä P, Heiskanen T, Hagelberg N, Mustola S, Forssell H, Kautiainen H, Kalso E: Validation of EQ-5D and 15D in the assessment of health-related quality of life in chronic pain. Pain 2017, 158:1577-1585.

3. Hamine S, Gerth-Guyette E, Faulx D, Green BB, Ginsburg AS: Impact of mHealth chronic disease management on treatment adherence and patient outcomes: a systematic review. Journal of medical Internet research 2015, 17. 
4. Huertas A, Palange P: COPD: a multifactorial systemic disease. Therapeutic advances in respiratory disease 2011, 5:217-224.

5. Agusti A, Edwards L, Rennard S, MacNee W, Tal-Singer R, Miller B, Vestbo J, Lomas D, Calverley P, Wouters E: Evaluation of COPD Longitudinally to Identify Predictive Surrogate Endpoints (ECLIPSE) Investigators Persistent systemic inflammation is associated with poor clinical outcomes in COPD: a novel phenotype. PLoS One 2012, 7:e37483.

6. Castillo RC, Wegener ST, Heins SE, Haythornthwaite JA, MacKenzie EJ, Bosse MJ, Group LS: Longitudinal relationships between anxiety, depression, and pain: results from a two-year cohort study of lower extremity trauma patients. $P A I N \otimes 2013,154: 2860-2866$.

7. Keeley P, Creed F, Tomenson B, Todd C, Borglin G, Dickens C: Psychosocial predictors of healthrelated quality of life and health service utilisation in people with chronic low back pain. $P A I N \otimes 2008$, 135:142-150.

8. Nicholl B, Macfarlane G, Davies K, Morriss R, Dickens C, McBeth J: Premorbid psychosocial factors are associated with poor health-related quality of life in subjects with new onset of chronic widespread pain-results from the EPIFUND study. PAIN® 2009, 141:119-126.

9. Raftery MN, Ryan P, Normand C, Murphy AW, de la Harpe D, McGuire BE: The economic cost of chronic noncancer pain in Ireland: results from the PRIME study, part 2. The Journal of Pain 2012, 13:139-145.

10. All AC, Fried JH, Wallace DC: Quality of life, chronic pain, and issues for healthcare professionals in rural communities. Online Journal of Rural Nursing and Health Care 2017, 1:29-57.

11. Gröhe H, Fachzeitschrift zu: Der Patientennutzen muss im Vordergrund stehen. Monitor Versorgungsforschung. Realität Qualität und Innovation der Gesundheitsversorgung 2016, 9:6-9.

12. Katz N: The impact of pain management on quality of life. Journal of pain and symptom management 2002, 24:S38-S47.

13. Yin S, Njai R, Barker L, Siegel PZ, Liao Y: Summarizing health-related quality of life (HRQOL): development and testing of a one-factor model. Population health metrics 2016, 14:22.

14. Emrani Z, Akbari Sari A, Zeraati H, Olyaeemanesh A, Daroudi R: Health-related quality of life measured using the EQ-5D-5 L: population norms for the capital of Iran. Health and Quality of Life Outcomes 2020, 18:1-8.

15. Huber MB, Felix J, Vogelmann M, Leidl R: Health-related quality of life of the general German population in 2015: results from the EQ-5D-5L. International journal of environmental research and public health 2017, 14:426.

16. Yfantopoulos JN, Chantzaras AE: Validation and comparison of the psychometric properties of the EQ-5D-3L and EQ-5D-5L instruments in Greece. The European Journal of Health Economics 2017, 18:519-531.

17. EuroQol Research Foundation,

18. Group TE: EuroQol-a new facility for the measurement of health-related quality of life. Health policy 1990, 16:199-208. 
19. Herdman M, Gudex C, Lloyd A, Janssen M, Kind P, Parkin D, Bonsel G, Badia X: Development and preliminary testing of the new five-level version of EQ-5D (EQ-5D-5L). Quality of life research 2011, 20:1727-1736.

20. Oppe M, Devlin NJ, van Hout B, Krabbe PF, de Charro F: A program of methodological research to arrive at the new international EQ-5D-5L valuation protocol. Value Health 2014, 17:445-453.

21. Xie F, Gaebel K, Perampaladas K, Doble B, Pullenayegum E: Comparing EQ-5D valuation studies: a systematic review and methodological reporting checklist. Medical Decision Making 2014, 34:8-20.

22. Goudarzi R, Sari AA, Zeraati H, Rashidian A, Mohammad K, Amini S: Valuation of Quality Weights for EuroQol 5-Dimensional Health States With the Time Trade-Off Method in the Capital of Iran. Value in health regional issues 2019, 18:170-175.

23. van Hout B, Janssen M, Feng Y-S, Kohlmann T, Busschbach J, Golicki D, Lloyd A, Scalone L, Kind P, Pickard AS: Interim scoring for the EQ-5D-5L: mapping the EQ-5D-5L to EQ-5D-3L value sets. Value in health 2012, 15:708-715.

24. Burström K, Johannesson M, Diderichsen F: Health-related quality of life by disease and socioeconomic group in the general population in Sweden. Health policy 2001, 55:51-69.

25. Parker L, Moran GM, Roberts LM, Calvert M, McCahon D: The burden of common chronic disease on health-related quality of life in an elderly community-dwelling population in the UK. Family practice 2014, 31:557-563.

26. Heyworth IT, Hazell ML, Linehan MF, Frank TL: How do common chronic conditions affect healthrelated quality of life? Br J Gen Pract 2009, 59:e353-e358.

27. Huber MB, Reitmeir P, Vogelmann M, Leidl R: EQ-5D-5L in the general German population: comparison and evaluation of three yearly cross-section surveys. International journal of environmental research and public health 2016, 13:343.

28. Saarni SI, Härkänen T, Sintonen H, Suvisaari J, Koskinen S, Aromaa A, Lönnqvist J: The impact of 29 chronic conditions on health-related quality of life: a general population survey in Finland using 15D and EQ-5D. Quality of Life Research 2006, 15:1403-1414.

29. Brazier J, Ara R, Rowen D, Chevrou-Severac H: A review of generic preference-based measures for use in cost-effectiveness models. Pharmacoeconomics 2017, 35:21-31.

30. Okura Y, Urban LH, Mahoney DW, Jacobsen SJ, Rodeheffer RJ: Agreement between self-report questionnaires and medical record data was substantial for diabetes, hypertension, myocardial infarction and stroke but not for heart failure. Journal of clinical epidemiology 2004, 57:1096-1103. 